\title{
eLearning a New Way for Saving: Guild's Survey as a Case Study
}

\author{
Abdelsalam Obedidat \\ Faculty of Information \\ Technology \\ WISE University, Amman Jordan \\ se.dept@wise.edu.jo
}

\author{
Amer Nizar AbuAli \\ Faculty of Information \\ Technology, \\ Philadelphia University, Amman \\ Jordan, \\ drabuali@yahoo.com,
}

\author{
Sameh Ghwanmeh \\ Faculty of Information \\ Technology \\ WISE University, Amman Jordan, \\ sameh@wise.edu.jo
}

\begin{abstract}
In the early days of eLearning, there was an awful lot of hype about expected results from eLearning initiatives. One of the biggest was about how much money organizations could save through eLearning. ELearning provides increased opportunities for delivering and taking part in learning, but building and delivering eLearning is typically not as inexpensive as we were once promised. Here are some of the more common costs associated with eLearning: Content development, Course design and development, Project management processes and tools, Authoring and multimedia development tools, Infrastructure, including Learning Management Systems. Although, better training may drive improved performance, many organizations still find themselves needing to reduce the costs of designing, building, and delivering eLearning. The main objective of this paper is discovering how eLearning could cut down the cost for organizations benefiting from Guild's survey.
\end{abstract}

Keywords: eLearning, Cost saving, LMS

\section{Introduction}

In December 2010, the eLearning Guild (hereafter called Guild) sent out requests asking members to respond to a Costsavings Survey. It asked respondents closed-ended questions about the sources of information they use to reduce eLearning project costs, and open-ended questions about specific resources used and tips for reducing eLearning project costs in a number of areas. Seventy-five people responded to the Costsavings Survey. Figure 1 shows the job focus of Gild's survey respondents. The bulk of respondents do a little or lot of everything, are instructional designers, or are involved in training, education, or certification direction.

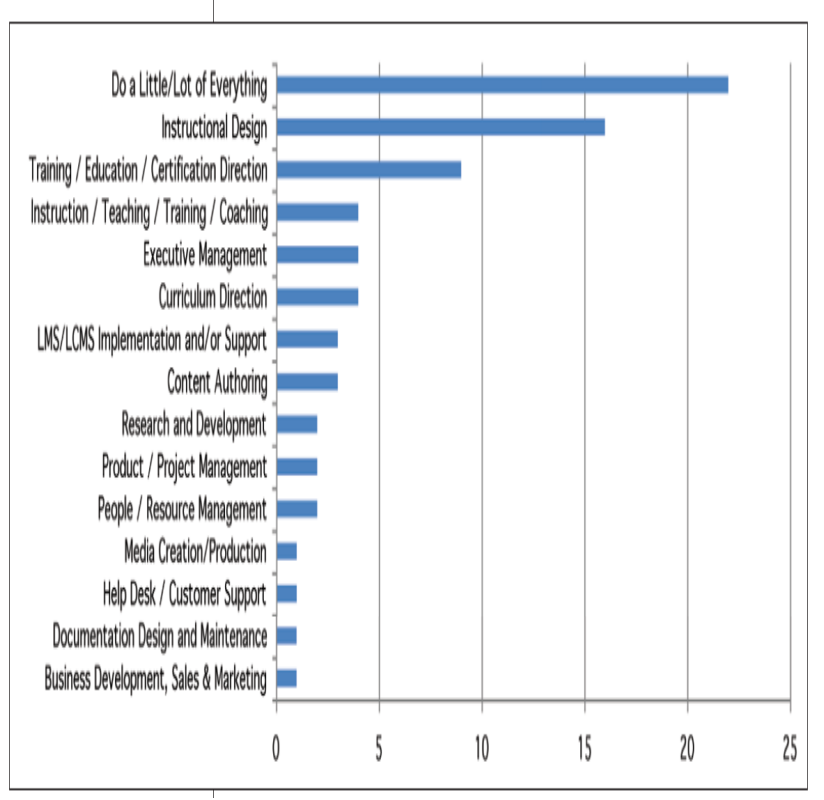

Figure 1: Number of respondents by job focus.

\section{Who Needs Cost Savings?}

The Guild's survey interviews with a selected group of respondents showed that being cost conscious is on all of their 
minds and is a way of life. The theme running through these respondents' minds is that you should view cost savings, for the most part, positively, not negatively

Bill Cushard [1], Chief Learning Officer for The Knowland Group in Lewes, Delaware, U.S. says he has always been cost conscious. "We think it's a good plan to never to get used to big budgets and large teams because that feeds complacency. If we are creative, we think we can do more without spending more.” Jayne Bartlett [2], Assistant Director of Technology Education Services at Geisinger Health System in Danville, Pennsylvania, U.S. agrees. "We have always looked for ways to be as lean as possible and still provide the level of education needed." She explains that Geisinger has a formal quality program where every department focuses on the best quality and the least cost, and her department's cost consciousness is part of this endeavor. Bartlett says that changes to the economy, and the ever-dwindling Medicare and Medicaid reimbursement, require all employees to look for ways to cut costs while still providing optimal healthcare services. Penny Spracht [3], Senior Instructional Designer, at Erie Insurance, in Erie, Pennsylvania, U.S. says saving money isn't that hard if you are creative. She finds plenty of resources that are either low or no cost. Mike Dickinson [4], Director, e-Learning and Curriculum, The SCOOTER Store, New Braunfels, Texas, U.S., like Bartlett, also uses some free tools. He feels that people in this field need greater financial awareness and cost conscious-ness. "We are not a revenue channel," he explains, "so our costs impact the bottom line. Therefore, we need to be more conscious of costs." He explains that the executives in his company communicate financial information regularly, so employees know how the company is doing and understand the need for financial prudence. "Plus, our ESOP (employee stock ownership program) helps motivate us all to watch the bottom line.”

From Guild's survey, respondent's ideas showed plenty of outof-the-box thinking. For some insight into how out-of-the-box thinking can reduce the costs for eLearning infrastructure and courses. Robin Mooren [5], who works in the Quality Assurance, Innovation, and Management Support department for Zonnehuisgroep Amstelland in Amsterdam, the Netherlands. He has found sharing knowledge with others in the same sector extremely valuable, and the cost savings quite impressive. For example, he describes how one of the organizations he knows was interested in exploring eLearning. His organization had researched eLearning, but found they were too small to make it work on their own. So six organizations, including Robin's, decided to further investigate LMSs and eLearning investments as a group. After finding that they had similar requirements, they pooled their funds for a custom LMS, tailored to very specific needs.
"Our next goal, he explains, “...is to for each of us to build an eLearning module that all can use, using the same authoring tool, and then swap these and change the branding. Mooren cut costs by nearly $80 \%$ using this approach, which makes eLearning very cost effective, instead of too expensive for his company.

\section{Cost-savings Tips: eLearning Courses}

From Guild's survey we list some tips from respondents about how to reduce costs and improve results for eLearning courses in general, including evaluating when it may be best not to create eLearning courses.

1. Assume a cost-savings mindset at the start of all course development. This includes starting with a rapid design in mind. Then add additional design and development resources only where genuinely needed.

2. Shorten courses. Courses should include only essentials. This reduces development and usage time. (Leaner's time is expensive, too)

3. Don't use "courses” for all topics. Use wikis for publishing processes and procedures, and let staff maintain and update these themselves. This may require selling this to management and staff.

4. Take advantage of screencasts. They're quick and easy to develop and you can use free tools such as Screen. For example, record informal five-minute screencasts with SMEs to share knowledge without a lot of expense.

5. Record Webinars for those who are not able to attend the live event. Combine these recordings into longer "courses" with exams and additional reading materials.

6. Develop once, use many times. See if there is overlap in your needs where you can develop courses together with people in the same business. This could work especially well for regulatory and compliance courses.

7. Try to not create eLearning that will only be used once. For on-the-job situations, consider creation of "huddle" sheets. These sheets are one-page reference guides that tell supervisors exactly what to say and do to train their team on a particular topic. They can include a brief scenario practice or discussion and usually last up to 20 minutes.

8. Combine technologies. For example, supplement asynchronous courses with synchronous role-plays. Get more out of the tools that are available to you. 
9. Provide mobile content for mobile staff. This makes content available to them and reduces the cost of having them have to come into the office for training.

10. Let learners create learning content. One respondent explained how his sales team creates simple videos for other sales people. They love it, and others learn from these videos as well.

11. Incorporate social interaction into asynchronous learning. Blogs, e-mail, wikis, discussion forums, and other tools are useful for support and engaging with facilitators and other learners. You may be able to improve learning and cut down on course size by adding social interaction. Participants may be able to respond to others' questions as well and this will lessen reliance on the facilitator, reducing costs. Note: If a message board or e-mail system is in place for participants to get help, you must monitor it and answer questions.

12. Improve social learning results by having a moderator. Blogs and wikis, for example, work better when someone can answer questions, guide users in content placement and formatting, seed the blog or wiki with new ideas or questions to increase user activity, and address conflicts or problem users. Great moderators understand the subject matter, are technically savvy, and will engage the user base. Given this set of requirements, the moderation role should be part of his or her job responsibilities and not an add-on duty.

13. Sell your courses externally to customers. This can help you become a profit center! You may have set ideas about what eLearning courses should look and act like, but eLearning (or any learning) should be primarily about sharing knowledge. And sharing knowledge doesn't always (and shouldn't always) involve formal training. Training can be expensive, and ideally you should use it when it's the best intervention for the need at hand. If you can facilitate knowledge sharing with less-expensive approaches, such as providing cheat sheets, wikis, job aids, or quickly developed screencasts, these cheaper alternatives may be just the ticket. And don't forget, if you reduce the number or projects that require full-blown eLearning solutions, your existing resources can do more.

\section{Cost-savings Tips: Tools}

The following are tips from about how to reduce costs and improve results with tools.

14. Use rapid tools. This reduces the learning curve and development time. Tools mentioned included Captivate, Articulate, and Lectora.

15. Use PowerPoint as your development "tool.” You can save PowerPoint files with audio and media as PowerPoint show files. No extra tools needed! The downside is large file sizes, minimal interaction, and no play bar to pause the course or skip ahead.

16. Use the incredible amount of free resources available. Here are the resources that were mentioned: stock images (Stock XChng), animation (Go Animate), audio editing (Audacity), image editing (Paint), stock media (Footage Firm), color design (Color Schemer), and course development (Course Lab). Jane Hart's blog[6] has a great list of free and inexpensive tools.

17. Don't spread your social learning across a wide variety of tools. Too many tools typically mean fewer users per tool. One of the benefits of social learning is that the users get support from each other and a larger base of users is preferable. Plus, more tools means more moderation and other costs.

18. You can do much of your development in freeware. SMEs can create the content themselves and you can publish as is, or dress it up and publish. Course Lab was mentioned as a free tool used for this purpose.

19. Work with colleagues to get discounts. Collectively you may be able to get multiple licenses of needed tools.

20. Master the nuances of the tools you use for greater efficiency.

21. Recycle licenses. For example, install a license for the person who will develop the eLearning module and then uninstall it and install it elsewhere where needed. Note: check the software license agreement for "one seat" licensing to ensure this is allowed by the software vendor.

22. Look at upgrades to existing tools to see if they can reduce your production time. For example, the new master slides capability in Adobe Captivate 5 assures that the design is consistent throughout. This can save a lot of time! One of the best things about eLearning today, as opposed to only a few years ago, is the range of great tools we have to use. And, as many respondents stated, there are many free tools to augment your existing toolbox. Sure, it can be overwhelming to learn and keep up with a changing toolset, but that's truly the reality of working in this field. See the Professional Development tips for some insights on how others manage to keep their heads above water.

\section{Cost-savings Tips: Project Management}

Most eLearning projects are more complex than most classroom-based learning projects. As a result, there are loads of details to deal with, and the amount of details increases as more people are involved. How do you gain control of this type of complexity? Project management! The following are 
tips about how to reduce costs and improve results from project managing your projects.

23. Use a project management tool so everyone is working with the same information. This saves hassles and rework.

24. Use collaboration software. A tool such as Microsoft Office SharePoint helps to manage eLearning projects. It is useful for housing links to the most recent draft, different versions of the storyboard documents, project schedules, progress of each module, and a custom list to manage client feedback. It's important, though, to train clients to use it.

25. Make sure that the client agrees to their review deadlines in advance. Do this before setting up the project schedule. Discuss how delays snowball, thus delaying future deliverables and increasing costs.

26. Use free synchronous tools for team brainstorming and working together. Tools such as Skype allow design teams to work together from a distance.

27. Use tools to allow multiple reviewers to review and comment online.

28. Get clients to validate the reviewer's comments to determine which fixes to make. Having clients validate reviewer comments and recommendations saves time in determining what fixes to implement. Otherwise you run the risk of making changes that will have to be undone.

Good project management processes (and tools) are necessary because problems with team communications and direction necessarily result in more time and effort. And more time and effort means greater cost and reduced capacity. Getting your project management processes in order can go a long way to helping you do more with less.

\section{Cost-savings Tips: Learning Management Systems}

Learning Management Systems are often complex and costly. One respondent described how important it is to develop clear and detailed requirements. Once we implemented our LMS, we realized we had some needs that we hadn't considered and now we're paying the price with unplanned customization. If we were to do this again, we would spend more time on determining the things we need.

The following are tips about how to reduce costs and improve results when planning to purchase a LMS.

29. Build a concise but very specific list of requirements. You can avoid the distractions of bells and whistles by comparing vendors' products based upon this list.
30. Don’t let scope creep happen when defining requirements!

31. Collect requirements from business partners and customers, even if you have disregarded their input initially. Then see if you can get their needs met for no additional cost from vendors.

32. Ask vendors to show you how to do what you need. Don't just accept a reply that it can be done. There's a difference.

33. Plan ahead. There's a steep learning and effort curve when implementing a LMS. If you plan for it, you'll save time and effort.

34. Consider a smaller LMS. There are smaller systems that cost less and may do everything you need.

35. Consider building your own LMS. You can use SharePoint for this purpose.

36. Use an open source LMS. Moodle is open source, meaning the source code is freely available. If your needs are small, the extra development needed to make this work for you can be minimal. (If your needs are large, the development needed to make it work may be too costly.)

37. Figure out how to optimize the capabilities of your LMS. By doing this, we were able reduce time spent on administrative duties.

38. Map authoring tools to the LMS. Check out how well your authoring tools work with any LMS applications you are considering. You can save a lot of time and hassle by making sure they can play well together.

39. Create good processes. Once you have the LMS, develop processes that others must follow when using it. This reduces the need to fix problems, which can be costly.

Learning Management Systems can be pricey and buying and implementing one can take a lot of time. Many organizations find that spending adequate time on the front end saves much time on the back end.

\section{Conclusion}

ELearning delivers increased opportunities for delivering and taking part in learning, but building and delivering eLearning is typically not as inexpensive as we were once promised. Common costs associated with eLearning, including: content development, course design and development, project management processes and tools, authoring and multimedia development tools, infrastructure, including learning 
Management Systems. Although, better training may drive improved performance, many organizations still find themselves needing to reduce the costs of designing, building, and delivering eLearning.

This paper provides numerous ways to achieve cost savings in organizations' work. It is based on Guild's survey respondents .Many tips are given in order to reduce cost using eLearning System.

\section{References}

[1] Retrieved on April 10, 2013, available from http://www.mindflash.com/blog/2011/04/learning-what-mattershow-to-focus-on-improving-business-results/

[2] Geisinger Health System Annual Report 2011, retrieved on April 10, 2013, available from http://www.geisinger.org/about/2011_AR_FINAL.pdf

[3] Erie Indemnity Company Annual Report 2011, retrieved on April 10, available from http://www.erieinsurance.com/about/2011AnnualReport.pdf

[4] Retrieved on April 10, 2013, available from http://www.articulate.com/blog/category/case-studies/page/3/

[5] Retrieved on April 10, 2013, available from http://www.hoovers.com/company-information/cs/revenuefinancial.Zonnehuisgroep_Amstelland_Thuiszorg_BV.0eabcc54c8 04c00c.html

[6] Retrieved on April 10, 2013, available from http://www.c4lpt.co.uk/blog/

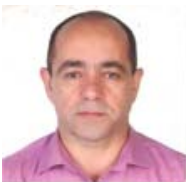

Dr. Abdelsalam Obeidat is currently working at WISE University as Head of Software Engineering Department. From September 2006 to August 2011, Dr. AbdelSalam worked as an associate professor and Head of Information Technology Department at Alzahra University College, Muscat, Oman. From September 2001 to August 2006, he worked as an assistant professor and Head of Computer Science at Alahlyya Amman University. From September 1993 to August 2000, Dr. AbdelSalam worked as an assistant professor at Computer Engineering Department, Yarmouk University Irbid, Jordan.

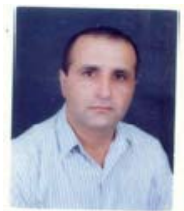

Dr. Amer Nizar AbuAli is an Associate Professor in CIS department, Faculty of Information Technology, Philadelphia University. He has more than 21 years of teaching, projects supervision and research experience. He attended and participated in many international conferences. Dr. Amer is a Peer reviewer for many conference and journal papers.

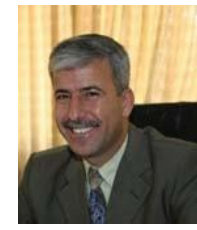

Prof. Sameh Ghwanmeh was born in Saham, Jordan, in 1963. He received his M.Sc. and Ph.D. in 1993 and 1996 respectively, from Liverpool University, UK and his B.Sc. in Electrical Eng. from Yarmouk University in 1986. He joined Yarmouk University, Jordan, in 1996 and spends 14 years in teaching and managerial positions, before joining Wise University, Jordan, in 2010. He has more than 17 years of Academic and Managerial experience in the IT field, including: academic teaching, administrative positions, consultations, and community services. To summarize: currently: Professor of Computer Science and Eng., Vice Dean and Chairman of the computer Science department, Wise University; 14 years of continuous Leadership and Managing Director of Computer and Information Center; 16 years of Quality Teaching, Research and QA; 7 years of ICT consultant to the Minister of Education; Rich Experience in Writing and Implementation of ICT and E-Learning Strategies; He has more than 45 publications in international Journals and conferences. Prof. Ghwanmeh is a member of JEA since 1986. 